DOI: $10.20472 / B M .2021 .9 .2 .002$

\title{
RISK MANAGEMENT: MODELING THE HUMAN RESOURCES RESPONSE TO THE COVID-19 SHUTDOWN
}

\author{
BARBARA A. MANKO, CEZARY PRZĘCZEK
}

\begin{abstract}
:
When an organization closes its business temporarily or transfers employees to work from home during the pandemic, it faces risks. The biggest risk is the loss of the most important assets of any company - the employee. Employees who have been left without a job may find a new one and not return to the old job when the business reopens. Further disruption may occur because some people prefer the organizational culture of face-to-face work, and working online is not the same. They experience loneliness and disruption from their personal life. Our model and survey are designed to help managers and leaders save their organizations. A business's effectiveness and reputation is built from customer and employee communication.
\end{abstract}

\section{Keywords:}

Organization Risks, Risks Management, Organization Performance, Organization Model, Organization Culture, Organization Effectiveness, Efficiency, Risks Management, Organization Performance, Organization Model

JEL Classification: C29, F20, L21

\section{Authors:}

BARBARA A. MANKO, Gannon University, Erie, United States, Email: manko001@gannon.edu CEZARY PRZĘCZEK, , Poland, Email: cezary.przeczek@gmail.com

\section{Citation:}

BARBARA A. MANKO, CEZARY PRZĘCZEK (2021). Risk Management: Modeling the Human Resources Response to the Covid-19 Shutdown. International Journal of Business and Management, Vol. IX(2), pp. 19-35., 10.20472/BM.2021.9.2.002 


\section{Introduction}

Every business faces risks, both internal and external. It is inevitable that a business of any size will have to learn to shift its tactics in response to market fluctuation, changes to supply chains, and dealing with a changing workforce. Add in a global pandemic that compounds issues that are already present while stacking on new government restrictions and the inclusion of additional safety measures, and business projections and strategies are thrown out the window in the interest of just saying afloat.

Businesses that have already established best practices, especially when it comes to strategic planning and risk management are better equipped to pivot when hurdles are placed in their way - even previously unimagined roadblocks. However, there are times when organizational change causes the business to fail. By analyzing other businesses through a survey that asked when they started planning for the coronavirus pandemic, and applying the results to a statistical model, this study aims to mitigate the risk of closing a business for a short-term reason.

Chapters:

1. Conflicts in Business...1

2. Covid-19 and Its Effects on Business...2

3. Administrative Management...3

4. Total Quality Management...5

5. Model of Strategic Human Resources Planning...8

6. Survey Responses to Covid-19 Shutdown ...11

\section{Conflicts in Business}

Conflict in business cannot be entirely avoided. Minor conflicts can actually have a positive effect as the business is forced to continuously reevaluate if the current strategies are effective. However, the avoidance of conflict can be just as harmful as the original problem, if not more, if the issue is not addressed.

While there are legitimate reasons to avoid conflict, such as the case of picking your battles with petty staff arguments, in general the reasons to avoid conflict lie more with the person involved not liking the way conflict makes them feel. For example, their reason may be a desire to avoid saying the wrong thing, or a fear of rejection, damaged or lost relationship, or even harm. For those in management especially, learning to overcome that discomfort is critical to building a desirable company culture.

The truth is, in any environment, negative emotions travel faster and further. By not addressing problems when they are small, they risk becoming actual stumbling blocks to the company. Having strategies to manage conflict can also place a business in good position to address the everyday struggles as well as unforeseen challenges, such as natural disasters, market crashes, or the coronavirus pandemic. Unfortunately, just ignoring a problem will not cause it to be magically solved or eliminated.

One conflict that is faced literally every day in business is the Resistance to change. There is an oft-quoted phrase from Rear Admiral Grace Murray Hopper that says, "The most damaging phrase in the language is 'We've always done it this way." People find disruptions to their normal routine inordinately disruptive, so when businesses had to decide whether to close temporarily or 
allow employees to work from home during the pandemic, it challenged the 9-to-5 workday that has been ingrained in the typical worker for decades. In response to this, workers experienced a loss of job security. Emotions surrounding the coronavirus were already running high in March 2020. What was this new virus? How would it affect everyone's life? How could businesses, schools, parents - literally everyone - adapt to conserve some sense of normalcy or work-life balance.

\section{Covid-19 and Its Effects on Businesses}

The Covid-19 pandemic's impacts were multi-faceted. Government mandates of what constituted "essential" business caused some jobs to be lost, temporarily or permanently. Schools went virtual, and many parents were suddenly juggling the roles of full-time employee and teacher in the same workday. The impacts are not over yet, and ripples will continue to influence the economy for years as global markets seek a path to recovery and attempt to maintain any beneficial lessons while getting rid of outmoded operations that no longer serve them. Cloyne et al. (2020) observe, "The effects of this unprecedented shock are very heterogeneous across individuals and interact with many pre-existing vulnerabilities across race and class. In the meantime, governments around the world have been searching for the best tools to protect their citizens and businesses during the period of rapid contagion and for ways of restarting the economy once the health risk starts to subside." Truly the effects of the pandemic were felt globally, but not necessarily equally. Blundell et al. (2020) agree and add, "Moreover, this pandemic-induced crisis is having impacts across multiple related aspects of life, from health to jobs and to family life, and these impacts are interrelated. The most vulnerable groups by socio-economic background and health status are also those that may be hit the hardest."

Initially, there may have been some pressure to work harder online, to prove that it would work and that it was effective and efficient. However, no matter how dedicated staff members may be, working from home is not the same as coming into the office. The meme that says, "This meeting could have been an e-mail," was undoubtedly proven thousands of times in 2020, but some interactions are just more effective face-to-face. Working from home carries inherent risks, such as pets or children interrupting, technology not working, and some loss of productiveness as most employees don't have access to the same business resources at home as they do in an office setting. Going in to work, and having a dedicated office space is inherently less disruptive than setting up a work station at home. Online work lost the face-to-face connection, and platforms to replace it, such as Zoom, have their own issues, such as those just mentioned and ones that have been newly discovered, like zoom fatigue.

In addition to the personal challenges each worker must face, online leadership requires a style change from many managers. Checking in with staff becomes intentional, and some workers may need more instruction and motivation than others, especially for employees that weren't as technologically savvy to begin with. Then, there is the transition back into the office once things open up again. Larue (2020) states, "Managers will have to find creative ways to ensure the safety of their workers in order to jumpstart their transition after the shutdown.... Unlike transitions following natural disasters, our infrastructures will not need rebuilding, this should make for a more rapid recovery once the transition to normalcy begins. On the other hand, different countries have different pandemic curves and different labor markets. Some countries will recover faster than others, but, in a globalized world, the slower countries will slow down the faster-recovering countries." Unfortunately, much of the insight and lessons that can be gained from this time in our 
history will only be made clear in hindsight. For now, analysis of what is working and what is not can help businesses to keep going or get back on their feet faster.

The good news is that managing the conflict of online work, or reestablishing employees in the workplace with new uncertainties and safety requirements and lessened interactions can be approached with the same tried-and-true strategies that good businesses have employed for years. Managing conflict effectively results in agreement, stronger relationships, building trust, and learning. Conflict resolution can be encouraged if the following strategies are put into place before the conflict begins:

- Eliminate negative interaction

- Conduct team building

- Promote friendship via social events

- Encourage compassion

- Stay positive

- Avoid gossip

- Be a role model

Implementing these measures can be effective in any organization if proper attention is given to the work climate. The results are: Motivation, Personality, Self-Efficacy, Culture, Commitments to Work, and Organizational Culture. Emphasis on the proper mind-set creates positive behavior, an environment that encourages leaders to take the risks, and group that understands the sum is more powerful than individuals.

An effective organizational culture

- $\quad$ picks up behaviors from another's

- emphasizes shared information

- follows up with the rules ad regulation

- encourages learning from each other

Our behavior at work changes based on the influence of those around us and the leadership's encouragement. Negative emotions always spread, but so do positive.

\section{Administrative Management}

It is important that management be concerned with managing the total organization. Henri Fayol (1841 to 1925), a French engineer and industrialist, was the first to identify the major functions of management: planning, organizing, leading, controlling, and coordinating.

- Planning. Mathrani and Mathrani (2013) used a business intelligence module to "translate decisions into risk-eliminating actions at the operational level." By simulating risk scenarios, they were able to create a "strategy-pull approach for deploying business strategies and decisions." Likewise in a study by Fugate et al. they were able to measure "logistics performance as a second-order formative construct, indicating that efficiency, effectiveness, and differentiation are not necessarily trade-offs, but rather are complementary." They found "empirical credence to the logistic performanceorganizational performance relationship." Schmiedel et al. (2014) measured "cultural fitness of [an] organization for process management." By using the analytics data available, organizations can go beyond theoretical and apply solutions to real-world 
scenarios. When it comes to the covid shutdown, having these logistics analytics in place would allow a business to route out the best way to stock a high commodity item such as hand sanitizer or toilet paper and have an advantage over the competition.

- Organizing. Knowing who makes the decisions and who actually does the work is important. "In most firms, decision-making power and authority are concentrated in the higher echelons of managerial hierarchies. Decision-making, in particular financial decision-making, is centralised and tightly controlled by top executives in most organisations. In addition, manager-level personnel are believed to be key informants because they should be familiar with general issues occurring within their firms, such as HRM policy, decision-making processes, management strategy, etc." (Jun et al. 2013; 2014). Managers who make decisions without understanding the operations at a lower level may create impossible situations for their employees by not taking into account all the factors. With many workers cutting hours, working from home, or creating a hybrid schedule to ensure coverage, it is even more important for manager and higher ups to have some knowledge of what essential staff are contributing to the business, who can be shuffled, and what duties are being neglected because there hasn't been enough cross training.

- Leading. "Modern studies regarding the employees' degree of satisfaction in what the work environment is concerned reveal a strong connection between the leadership style practiced by the manager and the achievements and the enthusiasm shown by the employees. Therefore, specialists have noticed that the motivational factors don't imply only material motivational factors, such as the salary, the work environment, but also a series of moral factors like the acknowledgement of one's merits, the appreciation of the effort invested (for example, being promoted in the company can validate the employees' competences) or the possibility that the employee has of organizing his/her own activity. By this it is meant that the rigid and authoritarian figure of the leader should fade off, which on various occasions inhibits creativity or the employee's power of making a decision, by having damaging aftermaths concerning the level of performance or the quality of the products" (CÂRSTINA et al. 2017). It is important that leaders have knowledge of what it takes for each job to be done, but also that they are able to trust that if they provide employees the right tools, they can be trusted to accomplish their goals. As mentioned previously, especially in March 2020 and into the following months, with the uncertainty at the heart of the epidemic and the job market, leadership was particularly important in reassuring workers that they would still have a job to come back to if they had to shut down and having workers want to return when the offer was available.

Controlling. The best way to control outcomes is by controlling the culture of the business. "Culture...goes beyond values and beliefs; it extends to its all operational parts, starts from hiring employees, salaries all HR processes, to profitability and resources allocation, managing risks and opportunities. Risk and risk management influences organizational culture, which is reflected in the strategic management and performance as the combination of efficiency and effectiveness. However, the alignment of risk management, organizational culture and its values is a fundamental change in that organization because it can be rejected if there is any inconsistency in cultural values. In the end, more discussions and in-depth analyses are still required to 
establish and identify the link between organization cultural values and risk management practices" (Abuzarqa et al. 2019). The culture of a business is something that survives outside the four walls of the cubicle. When there is true camaraderie and care for coworkers, staff will go the extra mile when they are facing stressors. Beyond company loyalty, it is a loyalty to one another and a shared desire to succeed.

-Coordinating. "We assume that on individual- as well as on team-level preexist some features determining relation's success, such as: open and effective collaboration, readiness to take responsibility for management, leadership division, autonomous motivation and work engagement" (Kożusznik et al. 2015). Coordinating all these aspects across the business gives a holistic approach that focuses on crunching the numbers and the humanity that the numbers represent. This was a fine balance that needed to be struck during the shutdown, as businesses had to decide if they would pay workers their full hours or partial hours, furlough them, or lay them off.

As we can see from the above example, behavioral science uses scientific research to develop theories about human behavior, which can be used to provide practical tools for managers. Chen et al (2019) state, "The innovation culture emphasises the organisation's, and its members', preparedness to accept changes and, hence, adopt and develop new management systems and practices. Failure to manage risk may be seen by stakeholders (particularly funders and donors) as a symptom of lack of ability to achieve goals and objectives which may have detrimental effects.... While, in general, organisational culture shapes desirable organisational behaviour and practices, our results showed that it is specific components of organisational culture." They conclude that "communication and training should emphasise managing for superior mean performance over the longer term so that short-term upside and downside performance variations can be minimised."

\section{Total Quality Management}

"There is a unique link between leadership qualities and organizational success. Leadership is the problem of many organizations but little attention is given to leadership-related research. It is recommended that leaders should demonstrate these leadership qualities to enhance organizational effectiveness and efficiency" (Olanrewaju \& Okorie 2019). Total Quality Management (TQM) is a comprehensive approach dedicated to continuous quality improvement, training, and customer satisfaction. Its main focuses are to:

- Make continuous improvement a priority.

- Get every employee involved.

- Listen to and learn from customers and employees.

- Use accurate standards to identify and eliminate problems.

TQM strives to form an organization that actively creates, acquires, and transfers knowledge within itself and is able to modify its behavior to reflect new knowledge. This could include working from home, using new software, and employing new methods of communications. "Organizational culture is central to organizational effectiveness and performance given the government context of increasing accountability and efficiency, and leaders are key players in establishing the culture within their agencies" (Vito 2020). Organizations vary regarding: "mission, vision, values; organizational structure; trust and safety; communication and sharing information; staff recognition and wellness; performance management and discipline" (ibid.) However, within a 
framework with shifting variables and internal and external pressures, TQM can still be used to create a learning organization. In order to do so, managers must perform three key functions or roles:

- Build a commitment to learning.

- Work to generate ideas with impact.

- Work to generalize ideas with impact.

These three goals can only be implemented effectively with communication. "Organizational communication, both internal and external, affects organizational efficiency and effectiveness and consequently, the objectives of the organization. Communication is one the elements of the organizational life which is taken for granted and most of the times overlooked. Effectiveness and efficiency are two basic management concepts, which determine the analysis of what and how needs to be done by the organization in order to attain the desired objectives. Now, a question arises: Why some organizations seem to be more effective than others and attain performance quicker? The answer could be an appropriate organizational system composed of multiple elements working smoothly together and all connected through good communication" (Popa 2016). Once this framework has been established, the goals of the company are shared by the members. This gives them a unique approach to challenges, because they are working as team.

Schwarz et al. (2020) sum it up well: "Despite what we know about how organizations and their members respond to change, organizations continue to spend an inordinate amount of time confronting, mitigating, and dealing with failure during change" (p. 160). The coronavirus pandemic is a double-edged swords in many respects. It has revealed the holes in our infrastructure that experts knew for years existed, but which bureaucracy didn't want to invest money in to fix. Comfort et al. (2020) observe, "The COVID-19 pandemic reveals a rare opportunity to redesign global and national systems for managing deadly risks, using science-based evidence and information communication technology, to identify, track, search, and share timely, valid data among nations, triggering innovation and collective action to build a resilient international community."

There is also the catch-22 that essential workers are expected to maintain the social distancing requirements, but because they have been in the midst of the largest allowable gatherings of people for the entire duration, they have also become immune, so to speak, to some of the concern that haunted people especially in the early days of the pandemic.

As one might expect, essential workers-who are less able to socially distance because of their jobs-report adhering to socially distancing behaviors less, and they also see themselves isolating for a fewer number of weeks. Given that attitudes appear to be primary drivers of social distancing behavior, public messaging may be particularly important for gaining compliance. While firmly held attitudes are difficult to change, our results regarding media consumption are suggestive of potential means by which public officials might win over residents reluctant to uphold social distancing. Given that consumers of written news media and those who follow COVID-19 news very closely tend to report stronger social distancing behavioral intentions, perhaps public officials should devote more attention to engaging with television and radio 
stations-media forms whose audiences appear less inclined to engage in social distancing presently or in the future. (Pederson et al., 2020)

With fluctuating unemployment and many works reevaluating their goals and priorities, this is also a time of change in the business market on a global scale. How business leaders attempt to return to "normal" or "a new normal" may determine whether a business survives in this new market. While there have been government stimulus packages and several bills passed in an attempt to prevent economic collapse, Larue (2020) states, "The extent to which the $75 \%$ wage subsidy will prompt employers to keep or rehire many of their employees remains to be seen. If successful, this program could make for a less chaotic transition to normalcy." One would think that governments and businesses could learn from the past and come up with effective strategies, but there is always disagreement about the best way to solve a problem, especially when it comes to finances. And as Costa et al observe, even with financial assistance, there is still a disconnect if businesses have the funds but can't fill slots for the workers they need:

The destruction of this "matching capital" in recessions, as employment links get severed in the downturn, has been shown to derail workers' careers, keep wages low and further dampen aggregate demand in the economy, A number of other policy tools can be used together to promote job creation, facilitate labour reallocation and protect workers and their families against economic deprivation. A direct approach is to take advantage of the low opportunity cost of public sector hiring to launch public investment projects that will also provide work experience and skills development for the unemployed. However, good matches will be difficult to make if there are systematic mismatches between the skills that unemployed workers have and the demands of the jobs being created. This is likely to be the case now, as the jobs where vacancies have held up during the lockdown tend to be highly skilled while low-skilled workers have been disproportionately affected by temporary and permanent job losses. Training in the workplace can be an important part of the solution. (Costa et al. 2020).

As the coronavirus effects were not equally felt among all demographics, so the effects of the recession have "created new divides" say Hupkau et al (2020), "The impact of the pandemic on the labour market as well as the volume of home production is likely to have consequences for the gender distribution of work. On the one hand, women tend to be over-represented in service industries that have been subject to lockdowns or social distancing measures. The recession caused by the pandemic has produced unprecedented economic losses and it has become clear that its effects have exacerbated existing inequalities along a number of dimensions, most notably socio-economic status and ethnicity, and have created new divides, for example between those who can work from home and those who cannot." With all of this in mind, the pandemic may seem insurmountable, but humans have proven their resilience once again, and businesses will find a way out and continue to thrive. The question is how seamless they can make that transition.

\section{Model of Strategic Human Resources Planning}

When it comes to the logistics of transitioning a large workforce from the office to a work-fromhome setting, there are two departments that are particularly effected: IT and human resources. There is the immediate question of whether the company even has the resources to allow a portion or a majority of their employees to work from home, with many considerations. Can they 
provide laptops? Do they have the software or the bandwidth capacity to allow people to access their files remotely? Is there sensitive information that will be put at risk?

Human resources must also immediately get to work with new policies to explain what is expected in this foreign environment. They must facilitate interaction between managers and staff to ensure best practices are being established and followed. And they are also largely responsible for translating the safety policies into workable solution.

For example, a manufacturing plant in Illinois realized that there was going to be a large-scale shutdown in March 2020. They knew they could qualify as an essential business due to the medical nature of their product, but they also knew that safety measures would need to be put in place. They made the decision to move as many of the office staff as possible to a work-fromhome model. Some of them were given laptops - mostly the people who already had them requisitioned for travel purposes - and the rest were allowed to log in remotely using RemotePC.

The plant staff was subjected to temperature checks every morning, with a registered nurse, which cause long socially-distanced lines in the parking lot before entry, and caused delays in starting the workday, even with communication to be early and the temperature time would be in lieu of clocking in. Hand sanitizing stations were installed, and masks were required if six feet of space wasn't able to be maintained in the large, open warehouse environment. Eventually, they were able to install infra-red cameras to automatically check temperature at the door, with manual checks for anyone who set off the alarm. At this point, they brought the office staff back, but the break rooms were still closed. These ever-evolving policies were communicated by human resources with e-mails, signage, and meetings.

Human resources also had to provide essential employee letters for anyone who had to travel into the office, coordinate any employees who had to quarantine because of exposure, and arrange to receive negative tests before allowing return to work. Then, they had to hire new staff to replace anyone who chose the option to be off until the shutdown was lifted and ensure that all departments had adequate coverage with cross-training. Because they already had a system in place that explained exactly what was expected in each area, with work instructions for each product, and detailed checklists showing where each weld or screw was to be placed, they were able to continue production through a very challenging time.

A human resources department cannot be expected to anticipate a pandemic, but one that is organized with the ability to evaluate current staff and train incoming staff effectively becomes the engine that drives the company through unknown waters. 
The following information comes from Strategic Planning for Human Resources_Let's Get Started by

Figure 1. A conceptual model of strategic human resource planning

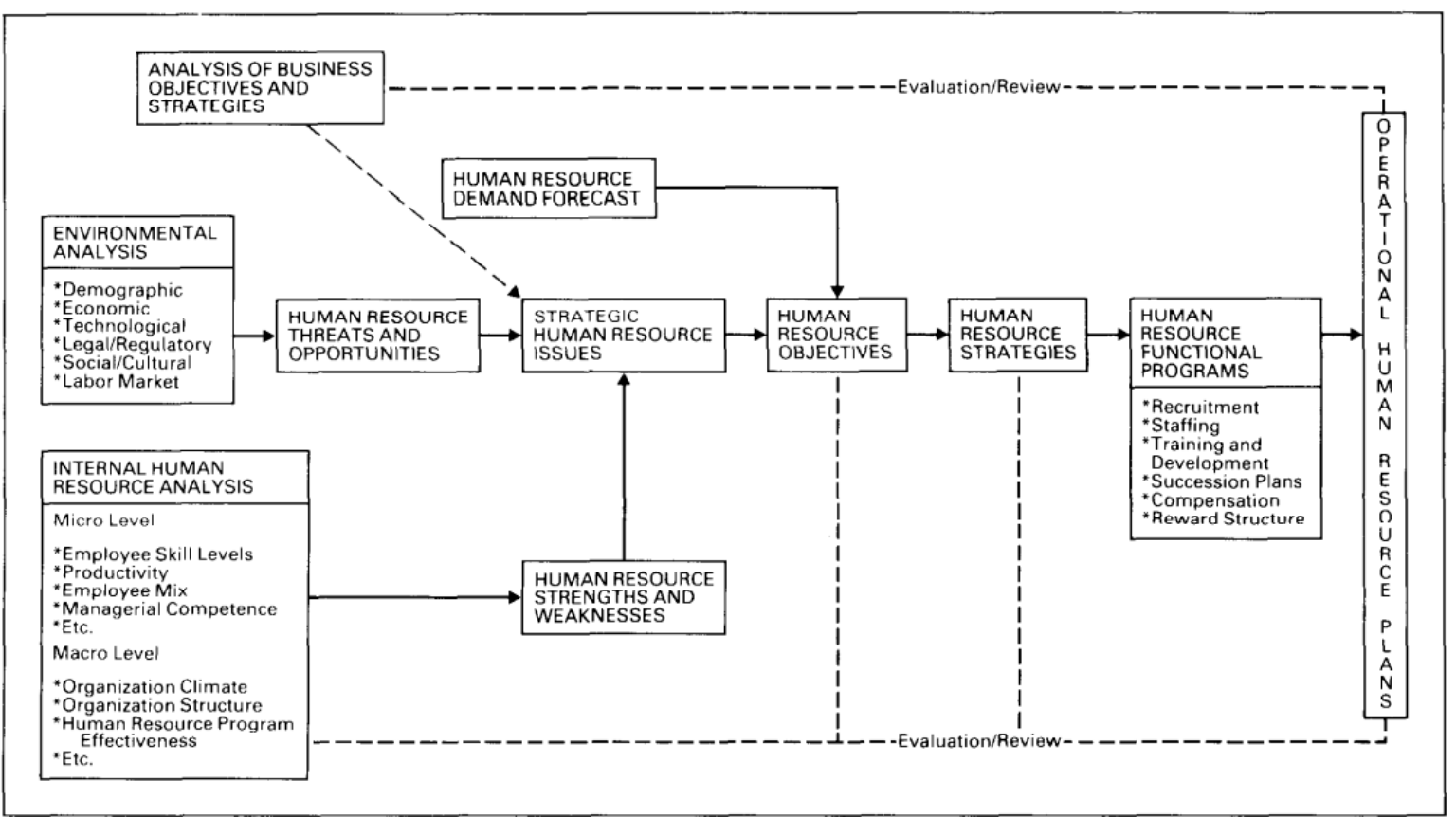

Source: Nkomo, S. M. (1988). Strategic Planning for Human Resources-Let's Get Started. Long Range Planning, 21(1)

S. M. Nkomo:

"Conceptually, strategic planning is consisting of three separate but interrelated activities: (1) establishing objectives; (2) developing strategies; and (3) formulating specific plans and programs to achieve objectives.

Strategic human resource planning may be defined as the process used to establish human resource objectives, to develop strategies for attaining objectives and to identify policies governing the acquisition, utilization, development and maintenance of human resources. There are essentially six key elements in a strategic human resource planning system. These elements and their interrelationships are shown at the model and each of these elements is briefly outlined.

\section{Environmental Analysis}

This step entails the systematic identification and analysis of key trends and forces in the external environment having a potential impact on the management of an organization's human resources. Changes taking place in the technological, economic, sociocultural, legal/regulatory and labor market environment must be monitored for their impact on human resource policies and programs. Objective knowledge about the environment is needed in the human resource strategy making process in order to achieve compatibility between the human resource management system and the external forces that affect, directly or indirectly, its goals, structure, size, policies, procedures or operations. If strategic human resource planning is to play a proactive role in the 
strategic planning process, a human resource oriented environmental scanning system becomes essential.

\section{Analysis of Business Objectives and Strategies}

Human resource objectives and strategies will be largely derived from overall organization strategic plans. For example, changes in business direction may involve major shifts in the nature of employees required and/or the work to be performed. However, at the same time, the strategic choices of an organization will be constrained by the quality and quantity of its current human resources or those available in the external labor market. The human resource forecast may reveal factors that influence the desirability or feasibility of certain corporate goals and the probability of achieving those goals.

The linkage between the objectives and strategies of an organization and strategic human resource planning can be understood by drawing upon the three levels of strategy identified in the strategic management literature: corporate level portfolio planning, business unit planning and functional level planning. For an organization, corporate level planning is concerned primarily with answering the question: What set of businesses should we be in? At the business unit level, planning focuses on how to compete in a particular industry or product/market segment. At the functional level, the principal focus of strategic planning is on the maximization of resource productivity, or simply, resource planning. This resource planning includes the determination of necessary requirements, plans for acquisition or generation of resources, and the allocation of resources. Examples of planning at the functional level would include production planning, financial planning and human resource planning.

\section{Internal Human Resources Analysis}

This step has two major dimensions. The first dimension involves a micro analysis of the current number of employees, their job-related skills, demographic make-up, performance levels (productivity), potential performance and work attitudes. Such an analysis can help to identify current human resource strengths and weaknesses. These data form a baseline of human resource capabilities which would be available for future organizational requirements. In addition to focusing on the basic nature of the work force, an analysis should also be made of macro level variables like organization climate and culture, organization structure, quality of work life, trends in absenteeism and turnover, and the current status and effectiveness of current functional area personnel systems. Upon completion of these analyses the organization should have a clear understanding of its present human resource position.

\section{Forecast Future Human Resource Demand}

Firms prepare a forecast of future human resource demand, but the vast majority rely heavily upon traditional forecasting techniques like replacement charts. This implies that human resource forecasting efforts have been largely confined to providing a supply of employees as replacements for existing business strategies rather than anticipating the impact of future business strategies on human resource needs. A strategic perspective requires both a quantitative and qualitative forecast of human resource demand. The end result should be not only a projection of staffing needs (number of employees for each job category) but an understanding of the qualitative mix that is needed to accomplish strategic objectives. 


\section{Generating and Developing Human Resource Strategies and Objectives}

Data from the previous analyses should be combined to develop human resource objectives and strategies. This phase involves defining the organization's desired human resource position and programs designed to reach that position. The human resource strategy basically involves modifying the internal configuration of an organization's human resources to assure successful alignment with both business strategies and the external environment. Human resource objectives will influence a wide range of employee activities such as productivity, skill levels and competencies, employee attitudes and staffing levels. Once objectives have been defined, functional area programming activities (e.g. recruitment, selection/staffing, training and development, reward systems) must be identified for achieving the objectives. It is critical that these specialized functions be integrated among one another and with business strategy and not be designed as disparate non-complementary programs."

\section{Survey Responses to Covid-19 Shutdown}

Figure 2. Survey Responses

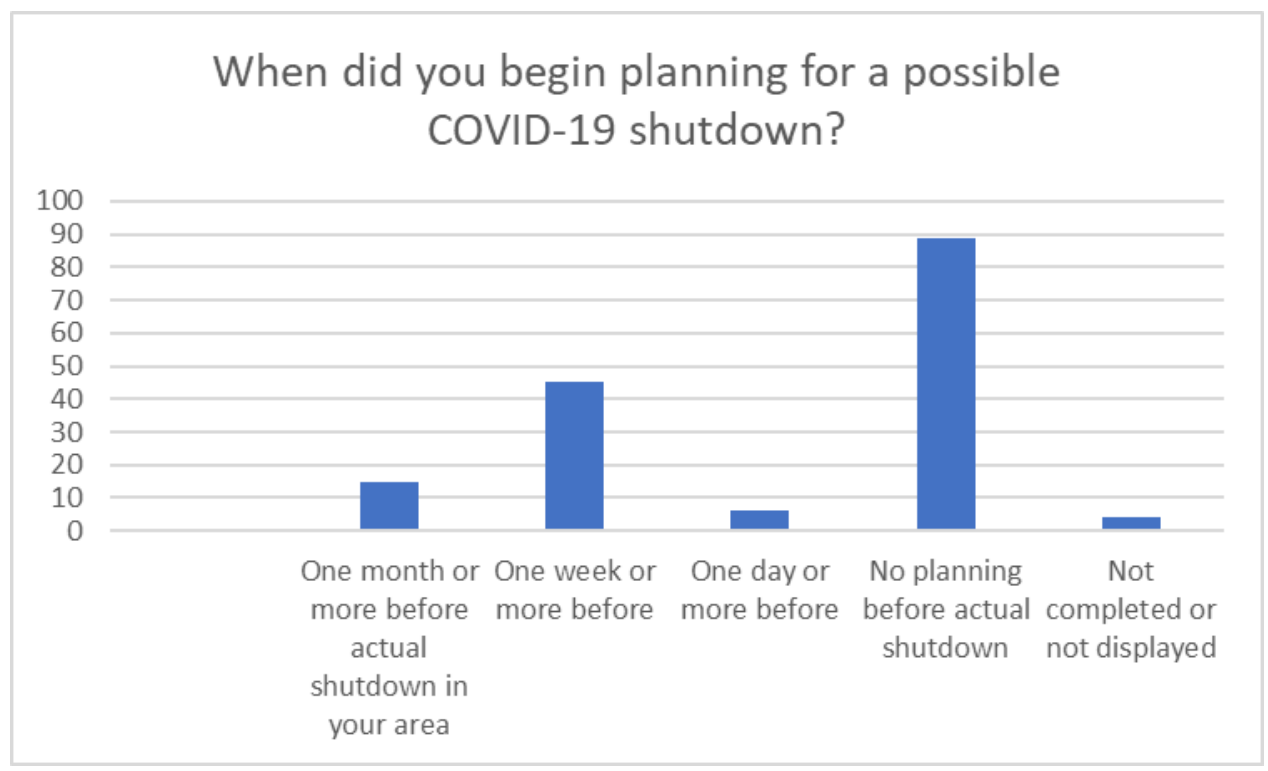

Source: Independent study data, Barbara Manko, 2021

Analysis: The total number of surveys sent equaled 307 , of which 157 or $51 \%$ of the responses were received. Of the $51 \%$ of responses received, $57 \%$ of those responses to the question "When did your organization begin planning for a possible COVID-19 shutdown?" states that their organizaion conducted no planning activities prior to shutdown. Four percent (4\%) stated that their organization conducted one to five days of planning before shutdown. Twenty-seven percent $(27 \%)$ stated that their organization began planning for shutdown one to three weeks before a shutdown, and ten percent (10\%) stated that their organization began planning for a shutdown one more or before a shutdown. Three percent $(3 \%)$ did not complete or did not display an answer to the question. 
Conclusion: Of the 157 responses 3 out of 5 organization conducted little to no pre-shutdown planing and 2 out of 5 organizations did conduct some pre-shutdown planning, leading to the conclusion that of the organizations most likely did have advanced knowledge that a shutdown for their organization was possible but chose not to plan for it or waited until a shutdown was imminent to conduct any type of pre-shutdown planning.

\begin{tabular}{|c|c|c|c|}
\hline \multicolumn{4}{|c|}{ Figure 3. Covid-19 Survey Response Data Table } \\
\hline Question Response Data: & Sent & Responses & $\%$ \\
\hline Total Surveys & 307 & 157 & $51 \%$ \\
\hline Response Data & Number & $\%$ & \\
\hline No planning before shutdown & 89 & $57 \%$ & \\
\hline One day or more before & 6 & $4 \%$ & \\
\hline One week or more before & 43 & $27 \%$ & \\
\hline One month or more before shutdown & 15 & $10 \%$ & \\
\hline Not completed or displayed & 4 & $3 \%$ & \\
\hline Total Responses & 157 & $100 \%$ & \\
\hline \multicolumn{4}{|l|}{ Analysis } \\
\hline Conducted little or no planning & & $61 \%$ & \\
\hline No planning before shutdown & $57 \%$ & & \\
\hline One day or more before & $4 \%$ & & \\
\hline Conducted some planning & & $37 \%$ & \\
\hline One month or more before shutdown & $10 \%$ & & \\
\hline One week or more before shutdown & $27 \%$ & & \\
\hline Other & & $3 \%$ & \\
\hline Not completed or displayed & $3 \%$ & & \\
\hline & & $100 \%$ & \\
\hline
\end{tabular}

There are many factors that may come into play at this point when it comes to the logic behind the decision-making that lead some companies to wait it out before making a decision. One wonders if they will be more proactive in the future, now that they have learned from this experience.

When it comes to the coronavirus pandemic, Spicer (2020) asks the question about how culture affects employees. He observes, "Rapid shifts in culture impact people's identity, their emotions and their well-being." There are questions that must be addressed of "the impact of shifts in organisational cultures on teams.... how changes in organisational cultures affect the performance of organisations... [and] how changes in organisational culture can transform wider field level cultures." In this case, the model as outlined above is a good way to "study culture beyond the classic qualitative and quantitative approaches" explains Schmiedel et al. (2018; 2019). "Those topics that relate most positively or negatively to the perception of organizational culture provide valuable insights for organizational research and practice. Regarding factors that 
are strongly positively associated with culture perceptions, we can identify topics referring to career options (career opportunity, career development, advancement opportunities), topics referring to formal rewards (salary raise, benefits), topics referring to the work environment (worklife balance, flexibility), and topics referring to social aspects (great people, help). Regarding factors that are highly negatively associated with culture perceptions, we can observe topics referring to management (poor management, management layers), topics referring to formal rewards (paycheck, bonus, low wage), topics referring to corporate aspects (company strategy, brand name, brain drain), and topics referring to social aspects (lying, listening, employee appreciation, employee treatment, laidback atmosphere)." All of these topics are compounded in times of stress. Brettel et al. (2015) said, "'Group culture is characterized by a focus on flexibility and on the development of close personal human relations; its core values are belonging, trust, and participation. In an organization featuring a group culture, the employees' commitment and their loyalty can be considered as key criteria for driving the firm's effectiveness. Due to its high degree of competitiveness, a rational organization culture leads to continuous internal improvements and new and novel ways of thinking about processes and products. Discussions about current solutions intensify as well, thus establishing a debate culture within an organization."

When it comes to staffing decisions at any time, human resources is tasked with keeping a healthy and happy workforce. It will be interesting to see in the coming years how the data reflects for companies that were able to plan ahead for a shut down and those that were forced to react on the fly. Returning to work created more demands, as some members of the workforce didn't feel comfortable returning to work due to risk of infection, found other opportunities, or chose to stay home with children. Undoubtedly, businesses with good training programs in place were able to transition more smoothly because they were prepared.

\section{Conclusion}

As we can see from the survey results, most businesses did not have a large amount of time to begin planning for shutdown. Then, once the shutdown occurred, they had to determine what the issues were going to be in moving forward before finding solutions. Having the ability to react and make plans quickly gives a business the advantage over the competition. While risks to the business such a global pandemic are hopefully not a common occurrence, the lessons learned from it translate into smaller problems that businesses address every day. Risk management and creating healthy company culture leads to better business no matter what the circumstances.

\section{Acknowledgment}

The authors first wish to acknowledge Assistant Professor Gary Williams from Clarion University College of Business Administration \& Information Sciences for helping with the survey. They would also like to acknowledge the many researchers cited in this paper. They express thanks to all the managers from around the world that work very hard to keep their businesses open and keep all the employees safe during the COVID-19 pandemic. Although the work for this paper was self-funded, the authors thank the institutions that have employed them and the colleagues they have met through them. Their support has enabled this work to be done 


\section{References}

Bates, J., Sharratt, M., \& King, J. (2014). Successful Outsourcing: Improving Quality of Life through Integrated Support Services. Healthcare Management Forum, 27(1_suppl). doi:10.1016/j.hcmf.2014.01.009

Blundell, R., Dias, M. C., Joyce, R., \& Xu, X. (2020). COVID-19 and Inequalities*. Fiscal Studies, 41(2), 291-319. doi:10.1111/1475-5890.12232

Brettel, M., Chomik, C., \& Flatten, T. C. (2014). How Organizational Culture Influences Innovativeness, Proactiveness, and Risk-Taking: Fostering Entrepreneurial Orientation in SMEs. Journal of Small Business Management, 53(4), 868-885. doi:10.1111/jsbm.12108

Chen, J., Jiao, L., \& Harrison, G. (2019). Organisational culture and enterprise risk management: The Australian not-for-profit context. Australian Journal of Public Administration, 78(3), 432-448. doi:10.1111/1467-8500.12382

Cloyne, J., Dias, M. C., Parey, M., \& Ziliak, J. P. (2020). COVID-19 and the Economy. Fiscal Studies, 41(2), 257-258. doi:10.1111/1475-5890.12234

Comfort, L. K., Kapucu, N., Ko, K., Menoni, S., \& Siciliano, M. (2020). Crisis Decision-Making on a Global Scale: Transition from Cognition to Collective Action under Threat of COVID -19. Public Administration Review, 80(4), 616-622. doi:10.1111/puar.13252

Dias, M. C., Joyce, R., Postel-Vinay, F., \& Xu, X. (2020). The Challenges for Labour Market Policy during the COVID-19 Pandemic*. Fiscal Studies, 41(2), 371-382. doi:10.1111/1475-5890.12233

Díez-Esteban, J. M., Farinha, J. B., \& García-Gómez, C. D. (2018). How does national culture affect corporate risk-taking? Eurasian Business Review, 9(1), 49-68. doi:10.1007/s40821-018-0105-0

Díez-Esteban, J. M., Farinha, J. B., \& García-Gómez, C. D. (2019). Are religion and culture relevant for corporate risk-taking? International evidence. BRQ Business Research Quarterly, 22(1), 36-55. doi:10.1016/j.brq.2018.06.003

Elkelish, W. W., \& Hassan, M. K. (2014). Organizational culture and corporate risk disclosure. International Journal of Commerce and Management, 24(4), 279-299. doi:10.1108/ijcoma-06-2012-0035

Fugate, B. S., Mentzer, J. T., \& Stank, T. P. (2010). Logistics Performance: Efficiency, Effectiveness, And Differentiation. Journal of Business Logistics, 31(1), 43-62. doi:10.1002/j.2158-1592.2010.tb00127.x

Gródek-Szostak, Z., Suder, M., Kusa, R., Sikora, J., \& Niemiec, M. (2020). Effectiveness of Instruments Supporting Inter-Organizational Cooperation in the RES Market in Europe. Case Study of Enterprise Europe Network. Energies, 13(23), 6443. doi:10.3390/en13236443 
Hupkau, C., \& Petrongolo, B. (2020). Work, Care and Gender during the COVID-19 Crisis*. Fiscal Studies, 41(3), 623-651. doi:10.1111/1475-5890.12245

Jun, W., \& Rowley, C. (2013). Change and continuity in management systems and corporate performance: Human resource management, corporate culture, risk management and corporate strategy in South Korea. Business History, 56(3), 485-508. doi:10.1080/00076791.2013.809522

Kinicki, A., \& Williams, B. K. (2020). Management: A practical introduction. New York, NY: McGrawHill Education.

Kożusznik, B., Chrupała-Pniak, M., \& Sulimowska-Formowicz, M. (2015). Team dimension of relational competence of organisation - psychological perspective. Management, 19(2), 7-20. doi:10.1515/manment-2015-0010

Larue, B. (2020). Labor issues and COVID-19. Canadian Journal of Agricultural Economics/Revue Canadienne D'agroeconomie, 68(2), 231-237. doi:10.1111/cjag.12233

Maradona, A. F. (2020). Do Individual Risk Attitudes, Experience, and Organizational Culture Influence the Conservatism of Indonesian Auditors? Jurnal Ilmiah Akuntansi Dan Bisnis, 15(1), 1. doi:10.24843/jiab.2020.v15.i01.p01

Mathrani, S., \& Mathrani, A. (2013). Utilizing enterprise systems for managing enterprise risks. Computers in Industry, 64(4), 476-483. doi:10.1016/j.compind.2013.02.002

Mitchell, G. E. (2012). The Construct of Organizational Effectiveness. Nonprofit and Voluntary Sector Quarterly, 42(2), 324-345. doi:10.1177/0899764011434589

Nkomo, S. M. (1988). Strategic Planning for Human Resources—Let's Get Started. Long Range Planning, 21(1), pp. 66-72. Nkomo, S. M. (1988). Strategic Planning for Human Resources-Let's Get Started. Long Range Planning, 21(1), pp. 66-72. https://doi.org/10.1016/0024-6301(88)90060-X

Olanrewaju, O. I., \& Okorie, V. N. (2019). Exploring the Qualities of a Good Leader Using Principal Component Analysis. Journal of Engineering, Project, and Production Management, 9(2), 142-150. doi:10.2478/jeppm-2019-0016

Pedersen, M. J., \& Favero, N. (2020). Social Distancing during the COVID -19 Pandemic: Who Are the Present and Future Noncompliers? Public Administration Review, 80(5), 805-814. doi:10.1111/puar.13240

Popa, B. M. (2016). Communicating for success. Journal of Defense Resources Management, 7(2), 79.

Schmiedel, T., Brocke, J. V., \& Recker, J. (2014). Development and validation of an instrument to measure organizational cultures' support of Business Process Management. Information \& Management, 51(1), 43-56. doi:10.1016/j.im.2013.08.005 
Schmiedel, T., Müller, O., \& Brocke, J. V. (2018). Topic Modeling as a Strategy of Inquiry in Organizational Research: A Tutorial With an Application Example on Organizational Culture. Organizational Research Methods, 22(4), 941-968. doi:10.1177/1094428118773858

Spicer, A. (2020). Organizational Culture and COVID-19. Journal of Management Studies, 57(8), 17371740. doi:10.1111/joms. 12625

Schwarz, G., Bouckenooghe, D., Vakola, M. (2020). Organizational change failure: Framing the process of failing. Human Relations, 74(2), 159-179. doi:10.1177/0018726720942297

Uğur, Ç. (2017). Analysing the relationship between organizational culture level and types of leadership of the employees. Health Care Academician Journal, 4(4), 347. doi:10.5455/sad.13-1513697265

ABUZARQA, R. (2019). The relationship between organizational culture, risk management and organizational performance. Cross-Cultural Management Journal, XXI(1), 13-20.

Dr. Barbara A. Manko's interest in the fields of Business Management and Information Systems and Technology led her to pursue a Doctorate of Science in Information Systems and Communications from Robert Morris University after completing her MBA in International Business. She has taught university courses in digital marketing, human resources, business management, strategic planning, and computer science, for both undergraduate and MBA programs. Her recent research, published in 2019 and 2020, focuses on technology management, online learning for students, and how online university programs prepare students to work remotely. Her upcoming research will be published soon in the Journal of Information Technology Teaching Cases. The title is "Teaching User-Friendly Web Design: A Case Study on Zillow.com in the Real Estate."

Cezary Przęczek MBA, is interested in human resources management, organizational behavior, organizational justice and NGO management. Currently working on Ph.D. thesis in the field of organizational justice and its influence on work engagement. Throughout his career worked for both public and private business sectors. He also held university courses in business management. Currently acting in the HR area in the private sector. 